\title{
Acknowledgement to Reviewers of Fibers in 2016
}

Fibers Editorial Office,

Published: 12 January 2017

MDPI AG, St. Alban-Anlage 66, 4052 Basel, Switzerland; fibers@mdpi.com

The editors of Fibers would like to express their sincere gratitude to the following reviewers for assessing manuscripts in 2016.

We greatly appreciate the contribution of expert reviewers, which is crucial to the journal's editorial process. We aim to recognize reviewer contributions through several mechanisms, of which the annual publication of reviewer names is one. Reviewers receive a voucher entitling them to a discount on their next MDPI publication and can download a certificate of recognition directly from our submission system. Additionally, reviewers can sign up to the service Publons (https://publons.com) to receive recognition. Of course, in these initiatives we are careful not to compromise reviewer confidentiality. Many reviewers see their work as a voluntary and often unseen part of their role as researchers. We are grateful to the time reviewers donate to our journals and the contribution they make.

If you are interested in becoming a reviewer for Fibers, see the link at the bottom of the webpage http://www.mdpi.com/reviewers.

The following reviewed for Fibers in 2016:

Aguiar, Jose

Almeida, Jose

Álvarez, José Ignacio

Caldas, Paulo

Candamano, Sebastiano

Carillo, Petronia

Chung, Chinkap

Ciminelli, Caterina

Cooney, Ralph

Corradi, Marco

Dhaliwal, Gurpinder Singh

Di Bella, Guido

Esmaeily, Asad

Farukh, Farukh

Fernando, Gerard

Focacci, Francesco

Forster, Aaron M.

Gangarao, Hota V.

Gilman, Jeffrey W.

González-Fonteboa,

Belén

Gordon, Stuart

Hawileh, R.A.

Hong, Soon Hyung

Houshyar, Shadi
Ingham, Jason

Islam, Mahbubul

Jensen, Benjamin D

Jun, Martin

Jung, In Hwa

Khyat, Kamal

Korwin-Edson, Michelle

Lafranche, Eric

Lai, Chien-Chih

Lawes, Simon

Lee, Bang Yeon

Lee, Byeong Ha

Lewis, Randolph

Lewis, Randy

Li, Hui

Lin, Jia-Horng

Liotier, Pierre-Jacques

Madurga, Rodrigo

Mahgoub, Mohamed

Martinelli, Enzo

Megaridis, Constantine

M.

Menna, Costantino

Mignani, Anna

Molimard, Jérôme

Monti, Marco
Muñoz, Eva

Natalio, Filipe

Nonappa, Nonappa

Oller, Eva

Ouagne, Pierre

Pan, Ning

Park, Soo-Jin

Pelletier, Mathew

Piergiovanni, Luciano

Pissadakis, Stayros

Rao, Smitha

Rhee, Kyong-Yop

Ribeiro, Maria C.S.

Salles, Vincent

Santulli, Carlo

Sarasini, Fabrizio

Schabikowski, Mateusz

Shaat, Amr

Simon, Jaan

Song, Kenan

Stefani, Alessio

Stéphane, Grange

Subramaniam, Prasad

Summerscales, John

Suragani Venu, Lalith

Taliercio, lberto 
Tapetado, Alberto

Thermou, Georgia

Tian, Tian

Triantafillou, Thanasis

Valenza, Antonino

\author{
Vougioukas, Emmanouil \\ Wang, Xin \\ Wong, Kok \\ Xiang, Dongxi \\ Yan, Libo
}

\author{
Yousif, Belal \\ Zanotti, Cristina \\ Zhang, Meng
}

(c) (1)

(C) 2017 by the authors; licensee MDPI, Basel, Switzerland. This article is an open access article distributed under the terms and conditions of the Creative Commons Attribution (CC-BY) license (http://creativecommons.org/licenses/by/4.0/). 